\title{
Evaluation of antifungal activity of seaweed extract (Turbinaria conoides) against Fusarium oxysporum
}

\author{
Ameer Junaithal Begum M. , P. Selvaraju and A. Vijayakumar \\ Department of Seed Science and Technology, Tamil Nadu Agricultural University, Coimbatore - 641003 (Tamil Nadu) \\ INDIA \\ *Corresponding author. E-mail: begumsst@gmail.com \\ Received: March 15, 2015; Revised received: August 17, 2015; Accepted: January 22, 2016

\begin{abstract}
The purpose of the study was to determine the anti fungal activity of seaweed (Turbinaria conoides) extract against root rot pathogen Fusarium oxysporum. Seaweed extract was prepared from the species $T$. conoides collected from Rameswaram coastal area of Tamil Nadu during December was used for this study. Different concentrations of the extract viz., $5 \%, 10 \%, 15 \%$ and $20 \%$ was evaluated for their antifungal activity against $F$. oxysporum using poisoned food technique along with control and carbendazim $(0.2 \%)$ as check. No mycelial growth $(0 \mathrm{~cm})$ was observed in $15 \%$ and $20 \%$ sea weed extract weed extract treated plates even after 6 days of incubation. Though the visible inhibition of mycelial growth was noticed in all the concentrations, the increased concentration of 15 and $20 \%$ had shown $100 \%$ inhibition. So, the lower concentration of $15 \%$ can be best in controlling the F. oxysporum fungi. GC-MS analysis of seaweed extract showing the presence of several antimicrobial compounds in seaweeds may be the reason for such inhibition.
\end{abstract}

Keywords: Antifungal,Carbendazim,Fusarium oxysporum, Torbinaria conoides

\section{INTRODUCTION}

Vegetables are the most sought after diets in Indian cuisine. Tomato (Lycopersicon esculentum Mill. $2 \mathrm{n}=24$ ), a self pollinated crop is one of the important solanaceous vegetable crops grown widely all over the world because of its special nutritive value and also it's wider spread production. Fusarium crown and root rot, caused by the fungus $F$. oxysporum f. sp. radicislycopersici is a serious problem in tomato cultivation. With no effective chemical treatments, root rot diseases are especially detrimental to these plants. Root rot diseases are soil-borne diseases that are most aggressive after heavy or continuous rainfall or improper irrigation. The diseases infect tomato plants through their root systems, causing symptoms to appear only after the infections have damaged the plants. The adverse impact of long-term use of synthetic chemical fungicides on physico-chemical characters, microflora and their micro-ecology of soil is well researched. Those chemicals lead to soil salinity and sodicity, decimating several soil flora and fauna with major impact on seed germination and growth. Several organic amendments are recommended for amelioration of such adverse conditions.

Arun kumar et al. (2005) evaluated the bioactive potential of seaweeds against plant pathogenic bacterium Xanthomonas oryzae pv. oryzae which cause blight in rice. Kumar et al. (2008) tested crude seaweeds extracts against the phytopathogenic bacterium Pseudomonas syringae causing leaf spot disease of the medicinal plant Gymnema sylvestris. The seaweeds are economically valuable resources, used as food, fodder, fertilizer and medicine and thus useful to mankind in many ways. Seaweed species are rich in amino acids and bio-plant enhancers and often regarded as underutilized bio-resources. More than 33 species of seaweeds are identified in coastal regions of Tamil Nadu. Many are being used as food, industrial raw materials, cosmetics and therapeutics for centuries.

Prabha (2013) revealed that Kappaphycus alvarezii has active secondary metabolites and also exhibited antimicrobial activity against Aspergillus flavus, Aspergillus fumigates and Candida albicans mainly in the methanolic extract of $K$. alvarezii and this may be mainly due to the presence of phenolic lipids, terepenes and phlorotannins. Ambika et al. (2014) reported that $G$. edulis, C. racemosa and $S$. myricocystum reduced the fungal mycelial growth of Alternaria porri at increased concentrations of $30 \%$. Pandithurai and Murugesan (2014) reported that extract of Spatoglossum asperum showed inhibition of $100 \%$ on mycelial growth of Aspergillus flavus, $57.14 \%$ of Candiada albicans and $54.75 \%$ of $C$. tropicalis. Renuka et al. (2014) reported that $1 \%$ extract of Chaetomorpha crassa had inhibitory effect on Macrophomina phaseolina, Sclerotium rolfsi and Pyricularia oryzae.

\section{MATERIALS AND METHODS}

Seaweed species, Turbinaria conoides was collected from Mandapam coastal areas and washed thoroughly 
with seawater 3-4 times to remove the sand particles, debris and marine epiphytes. Then it was chopped into small pieces and dried under sun for 4 days followed by oven-drying for 24 hours at $60^{\circ} \mathrm{C}$. Then, the dried material was coarsely ground. $500 \mathrm{~g}$ of the powder was added with $200 \mathrm{ml}$ of acetone and kept overnight after vigourous shaking. Then, the solution was decanted (alcoholic extract) and the residue was mixed with $300 \mathrm{ml}$ of distilled water. The mixture was boiled for 20 minutes and the solution was decanted (aqueous extract). Both aqueous and alcoholic extracts were mixed together and the volume was made upto $500 \mathrm{ml}$. The solution was considered as $100 \%$ concentrated solution and stored under refrigerated condition at $4^{0} \mathrm{C}$ (Ramamoorthy and Sujatha, 2007).

In vitro evaluation of fungi toxic effect of SWE on the radial growth of the fungi Poisoned food technique (Grover and Moore, 1962): The effect of fungicides and plant extracts on the growth of the pathogen was studied using poisoned food technique.

The fungicide and plant extracts were added separately to the autoclaved and melted potato dextrose agar media. The poisoned agar medium was poured into sterilized plates and allowed to solidify. Then the plates were inoculated with the test fungus by placing uniform disc of $9 \mathrm{~mm}$ diameter from 4 days old culture grown on potato dextrose agar medium. The diameter of the fungal colony was measured once in $24 \mathrm{~h}$. The medium without fungicides and plant extracts served as control and the mean inhibition percentage was worked out. Three replications were maintained at the laboratory temperature $\left(28 \pm 1^{\circ} \mathrm{C}\right)$. The per cent inhibition of the growth of the test fungi was calculated by the formula of Vincent (1927).

$$
I=\frac{100 \times(C-T)}{C}
$$

Where, $\mathrm{I}=$ Per cent inhibition of fungal growth; $\mathrm{C}=$ Growth in check; $\mathrm{T}=$ Growth in treatment

Statistical analysis: The data obtained from different experiments were analysed for the ' $F$ ' test of significance following the methods described by Panse and Sukhatme (1999). Wherever necessary, the per cent values were transformed to angular (Arc-sine) values before analysis. The critical differences (CD) were calculated at 5 per cent probability level. The data were tested for statistical significance.

\section{RESULTS AND DISCUSSION}

Based on the results obtained, all the concentrations (5 $\%, 10 \%, 15 \%$ and $20 \%$ ) of seaweed extract showed considerable inhibition on mycelial growth of $F$. oxysporum (Table 1). But, the increased concentrations of 15 and $20 \%$ showed maximum inhibition of $100 \%$ on even sixth day after incubation (Table. 2). Table 1 showed that the control plates had shown fungal |mycelial growth after 24 hours of incubation onwards. It was lower $(0.5 \mathrm{~cm})$ in the initial days and keeps on increasing gradually and grown towards the periphery $(7.5 \mathrm{~cm})$ of the Petri plate on seventh day after incubation. The carbendazim treated plates had not shown mycelial growth $(0 \mathrm{~cm})$ upto fourth day. But, it started to grow from fourth day onwards and attained $1.5 \mathrm{~cm}$ on seventh day with $80 \%$ inhibition over control. $5 \%$ SWE treated plates had not shown mycelial growth upto fourth day and $1.3 \mathrm{~cm}$ diameter fungal mycelial growth was notices on fifth day and $3.4 \mathrm{~cm}$ diameter of mycelial growth was seen on seventh day with $54.67 \%$ inhibition over control. In $15 \%$ and $20 \%$ treated plates, no occurrence of growth was noticed from first day upto sixth day after incubation with $100 \%$ inhibition over control but 1.7 $\mathrm{cm}$ and $0.3 \mathrm{~cm}$ diameter fungal mycelial growth was noticed on seventh day in $15 \% \& 20 \%$ treated plates respectively (Figure. 1). It was revealed that the seaweed extract of $10 \%$ obtained from brown seaweed Turbinari coinoide was effective in controlling the growth of $F$. oxysporum. Similar antifungal effect was studied in Sargassum wightii by Ambika et al. (2014) in onion; in Spatoglossum asperum by Pandithurai and Murugesan (2014) in rice; in Chaetomorpha crassa by Renuka et al. (2014) in rice. The reason may be due to the presence of antiviral, antibiotic, anti-neoplastic, antifouling, antiinflammatory, cytotoxic and antimitotic (Plaza et al., 2003 De Felicio et al., 2010; Peres et al., 2012) substances in sea weeds. Bioactivity of diverse

\begin{tabular}{|c|c|c|c|c|c|c|c|c|}
\hline \multirow[t]{2}{*}{ SWE concentration } & \multicolumn{7}{|c|}{ Mycelial growth (cm) } & \multirow[t]{2}{*}{ Mean } \\
\hline & I day & II day & III day & IV day & $\mathrm{V}$ day & VI day & VII day & \\
\hline Control & 0.0 & 0.5 & 1.7 & 3.9 & 6.5 & 7.1 & 7.5 & 3.9 \\
\hline Carbendazim $0.2 \%$ & 0.0 & 0.0 & 0.0 & 0.0 & 0.1 & 1.2 & 1.5 & 0.4 \\
\hline $5 \%$ & 0.0 & 0.0 & 0.0 & 0.0 & 1.3 & 2.8 & 3.4 & 1.1 \\
\hline $10 \%$ & 0.0 & 0.0 & 0.0 & 0.0 & 0.0 & 1.5 & 2.6 & 0.6 \\
\hline $15 \%$ & 0.0 & 0.0 & 0.0 & 0.0 & 0.0 & 0.0 & 1.7 & 0.2 \\
\hline $20 \%$ & 0.0 & 0.0 & 0.0 & 0.0 & 0.0 & 0.0 & 0.3 & 0.0 \\
\hline Mean & 0.0 & 0.1 & 0.3 & 0.7 & 1.3 & 2.1 & 2.8 & \\
\hline & & $\mathbf{T}$ & & & D & & TxD & \\
\hline SEd & & 0.00175 & & & 0.00189 & & 0.00464 & \\
\hline CD (0.05) & & 0.00464 & & & 0.00377 & & 0.00923 & \\
\hline
\end{tabular}

Table 1. Effect of seaweed extracts against mycelial growth of $F$. oxysporum. 


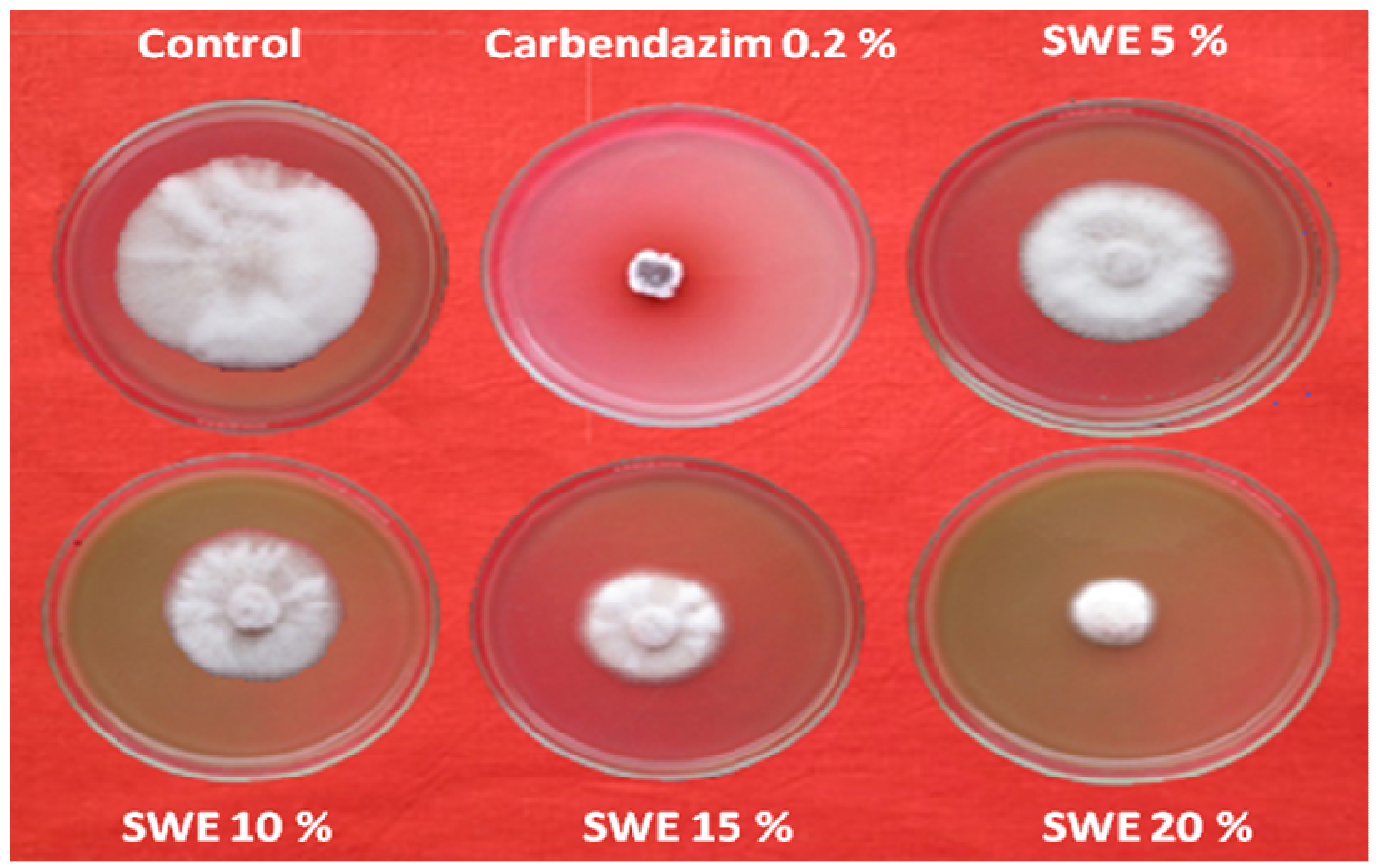

Fig. 1. Mycelial growth of $F$. oxysporum in media poisoned with sea weed extract.

secondary metabolites and other compounds extracted from seaweeds play an important role in prevention of different serious diseases. These biogenic compounds also have antibacterial, antialgal, antifungal properties (Paul and Puglisi, 2004; Bhadury and Wright, 2004). Prabha (2013) revealed that Kappaphycus alvarezii has active secondary metabolites and also exhibited antimicrobial activity against Aspergillus flavus, A. fumigates and Candida albicans mainly in the methanolic extract of $K$. alvarezii and this may be mainly due to the presence of phenolic lipids, terepenes and phlorotannins.

\section{REFERENCES}

Ambika, S., Sujatha, K. and Balakrishnan, K. (2014). Antifungal activity of seaweed extract against Alternaria porri in onion. In: National Seminar on Algae for sustainable agricultural production, Madurai, Tamil Nadu, India, Pp: 87.

Arun kumar, K., Selvapalam, N. and Rengasamy, R. (2005). The antibacterial compound sulphoglycerolipid palmitoyl3-0 (6'-sulpho- $\alpha$ quinovopyranosyl)-glycerol from sargassum wightii Greville (Phaeophyceae). Botanica Marina, 40: 441-445.

Bhadury, P. and Wright, C.P. (2004). Exploitation of marine algae: biogenic compounds for potential antifouling application. In Planta, 219: 561-578.

Kumar, C.S., Raju, D., Sarada, V.L. and Rengasamy, R. (2008). Seaweed extracts control the leaf spot disease of the medicinal plant Gymnema sylvestre. Indian J. Sci. Technol., 1: 93-94.

Pandithurai, M. and Murugesan, S. (2014). Evaluation of antifungal activity of seaweed extracts from marine brown alga Spatoglossum asperum. In: National Seminar on Algae for sustainable agricultural production, Madurai, Tamil Nadu, India, Pp: 89.
Paul, V.J. and Puglisi, M.P. (2004). Chemical mediation of interactions among marine organisms. Nat. Prod. Rep., 21: 189-209.

Prabha, V, Prakash, D.J. and Sudha. P.N. (2013). Analysis of bioactive compounds an antimicrobial activity of marine algae Kappaphycus alvarezii. International Journal of Pharmaceutical Sciences and Research, 4 (1): 306-310.

Renuka, R, Jeyalakshmi, C. and Rettinassababathy. (2014). Studies on antifungal and growth promoting potentialities of algal extracts under in vitro conditions. In: National Seminar on Algae for sustainable agricultural production, Madurai, Tamil Nadu, India, Pp: 91-92.

Peres, J.C.F., De Carvalho, L.R., Gonçalez1, E., Berian, L.O.S., Felicio, J.D. (2012). Evaluation of antifungal activity of seaweed extracts Ciênc. agrotec., Lavras, 36 (3): 294-299.

De Felicio, R. (2010). Trypanocidal, leishmanicidal and antifungal potential from marine red alga Bostrychia tenella J. Agardh (Rhodomelaceae, Ceramiales). Journal of Pharmaceutical and Biomedical Analysis, 52: 763-769.

Plaza, L., De Ancos, B. and Cano, P. (2003). Nutritional and health-related compounds in sprouts and seeds of soybean (Glycine max), wheat (Triticum aestivum L.) and alfalfa (Medicago sativa) treated by a new drying method. European Food Research and Technology, 21: 138-144.

Panse, V.G.N. and Sukhatme, P.V. (1999). In: Statistical methods for agricultural workers. ICAR, Publication, New Delhi, Pp. 327-340.

Vincent, J.M. (1927). Distortion of fungal hyphae in the presence of certain inhibitors. Nature, 159: 850.

Grover, R.K. and Moore, J.D. (1962). Toximetric studies of fungicides against brown spot organism Sclerotia fructicola and S. laxa. Phytopathology, 52: 876-880.

Ramamoorthy, K. and Sujatha, K. (2007). Effect of seaweed extracts on the ageing of black gram seeds. Seaweed Res. Utiln., 29 (1 \& 2): 119-127. 